\title{
INNOVATION POLICY AND PATENT STRATEGIES OF PHARMACEUTICAL COMPANIES ECONOMIC AND SOCIAL ASPECTS
}

\section{Rachinska I. M.}

\section{INTRODUCTION}

The creation of innovative drugs is an expensive and complex process. Thus, according to the European Federation of Pharmaceutical Industries Associations (EFPIA), the average cost of developing a new drug is about $\$ 1.5$ billion. (1.2 billion euros), and the time from the beginning of the development of the drug to its entry into the market on average reaches 12-13 years. In addition, on average, out of 10,000 molecules that go through all stages of development, preclinical and clinical trials, only 1 or 2 active ingredients receive permission for commercial marketing as a drug.

The introduction of new medicines into circulation is controlled by the national administrative bodies responsible for the quality, efficiency and safety of medicines, the so-called pharmacological supervision bodies, which carry out the registration of the drug and confirm it with a special document. This registration is carried out on the basis of data confirming the clinical efficacy and safety of the drug, which takes an average of 8 to 10 years to obtain.

It should be noted that the permissive administrative procedure for commercial use is established by law not only for medicines but also for some other products: food and barberry additives, cosmetics, medicines for animals or veterinary biological products, plant protection products, agrochemicals, medical devices, etc. However, this monograph will consider only those provisions of legislation and procedures relating to medicines for humans.

The need for testing and registration of medicines leads to the fact that they enter the market, as a rule, after 5-10 years or more from the date of filing a patent application, the object of which is the drug. Thus, the actual use of such a patent is possible only after the registration of the drug by the pharmaceutical supervision authorities and before the expiration of its validity.

Based on a study of more than 300 types of medicines on the European market, EFPIA concluded that the effective monopolistic commercial use of a patented drug is on average about 8 years due to the length of the drug trials for its registration both in Europe and in other countries. 
In order to ensure that the patent holder can exercise monopoly rights in the pharmaceutical field during the period of validity of the patent, as is the case in other industries, the national patent laws of many countries have introduced a provision on the extension of the patent term, the object of which is the product. For the first time this provision on the extension of the patent term to 5 years was introduced in the patent laws of the United States in 1984, a Similar rule was introduced in 1987, the patent law of Japan.

In 1991, the European patent Convention (EPC) was supplemented by a new version of part 2 of article 63 of the EPC, according to which the powers of the holder were granted the right to continue the 20 -year term of the European patent or to provide appropriate protection after the end of this period on the same terms as apply to national patents:

a) in the event of a state of war or a similar emergency in that state;

b) if the subject matter of a European patent is a product or a method of manufacturing or using a product which, before being put into circulation, must undergo an administrative authorization procedure established by law.

That is, the EPC provided for two mechanisms for such a European patent to continue the effective monopoly commercial use of the patented drug: the first-by extending the 20-year term of the patent, the second-through the provision of appropriate protection after the expiration of this term.

In the EU member States, Council regulation (EEC) no 1768/92 on the introduction of the certificate of additional protection of medicines, adopted by the economic Commission for Europe on 18 June 1992, was developed for the harmonization and unification of national legislation in the field of legal protection of inventions, as well as to protect the interests of drug manufacturers. The Regulation introduced in all EU member States a special form of additional protection of medicines-complementary protection certificate, SPC.

The monograph uses the term certificate of additional protection because the certificate is a legal document that grants its owner the same rights as a patent for an invention, and has the same restrictions and obligations.

It should be noted that the world intellectual property organization standard ARTICLE 9 "recommendations on bibliographic data concerning patents and certificates of additional protection (SPC) and related, in the official translation into Russian as well as into Ukrainian, also uses the term "certificate of additional protection".

But the Legal dictionary gives the following definition of "certificate". Certificate (FR. certificate, from lat. Certified-certify) - the document certifying any fact (for example, quality of goods, navigation of the vessel, the medical certificate on vaccinations, etc.). That is the certificate certifies the fact but not the right. 
The purpose of this article is to study the legal regulation of the extension of the term of protection of medicines using the mechanism of extension of the patent, the object of which is the drug, that is, patent law and using a special form of additional protection of medicines - certificate of additional protection (CAP), coverage of the practice of these mechanisms in different countries of the world as well as regulatory and practice of extension of the patent for the invention in Ukraine.

\section{Patent protection of original medicines}

Patent protection of inventions performs a number of economic functions. The first, the most famous of them is the stimulating function. It is based on the assumption that in the absence of patent protection, inventors will not be able to receive income from their intellectual development, which in turn will lead to negative consequences in society as a whole. There will be less innovation than society desires. Therefore, society grants a timelimited monopoly on inventions, believing that the cost in the form of higher prices to consumers through the granting of a monopoly, will be overshadowed by the benefits of innovation.

The second function is the transaction function. The existence of patent protection is defined as a necessary precondition for the emergence of a market for technology and specialized technology suppliers. The existence of patent protection contributions to collaborative research are widely recognized as a contributing factor to collaborative innovation (for example, if a company licenses a patented invention to another firm that is better able to bring it to market) ${ }^{1}$.

In practice, the stimulating and transactional functions are mutually related. Patents can facilitate revenue sharing among those who contribute to this research process. This, in turn, affects the amount of incentives available to the next inventors. Obtaining patent rights can limit duplication of innovation efforts while maintaining, in some cases, sufficient incentives to further develop products under the control of the patent owner. A number of studies have shown that strong and broad patent protection, especially of early "early" research, can also deter subsequent improvements to the innovation of subsequent inventors, thus creating obstacles to technological progress.

The third function that patents perform is the disclosure function. Disclosure of technical information that would otherwise be kept secret is an important aspect of all research and development and acts as a compensation

\footnotetext{
${ }^{1}$ Worker L. the Problem of evergreen patents in Ukraine. Intellectual property in Ukraine. 2012. No. 8. P. 20-26.
} 
for legal protection in the agreement between the inventor and the society. It is indispensable that the information disclosed in the patent documentation should enable the invention to be reproduced by a person skilled in the art. In practice, this may require special skills, knowledge of production secrets (know-how) and additional technologies. Limitations in the process of studying patents and the quality of the information disclosed by the applicant may in some cases prevent the possibility of reproducing the invention.

The value of patents also lies in their fourth - signal function. Patent ownership can serve the purpose of signaling a firm's innovative capabilities and increasing its ability to raise non-negotiable capital, especially through venture capital financing. This function is particularly important in the biotechnology sector, where new firms rely on their protected intellectual capital to raise funds.

Intellectual property rights (IP) and wine patents interact in a complex way with policies in other areas, both nationally and internationally. Although the IP policy is national, it has an impact on the results that have been reflected in the Agreement on trade-related aspects of intellectual property rights (trips) and numerous other bilateral and multilateral agreements. At the national level, IP rights can be affected by policies in other areas, including competition, pharmaceutical pricing, government procurement and others.

The efficiency of the pharmaceutical industry not only at present, in the near future, but also in the long term depends to a large extent on the clarity and transparency of the mechanism, which ensures IP protection, on the perfection of the legal norms regulating this process. It is important to take into account that the terms for which this protection applies, is the very stumbling block around which real legal battles of the main players of the pharmaceutical market - manufacturers of medicines (hereinafter - drugs) often unfold ${ }^{2}$.

Originator companies focused on the production of brands that require the longest terms of protection of their products in order to recoup the costs of $\mathrm{R} \& \mathrm{D}$, reinvest in the replenishment of product lines, that is, to support the further development of their innovative developments. Generic companies, whose number and influence has increased significantly in recent years, are interested in reducing these terms, which gives its benefits "here and now" both to the companies themselves and to health care, since it allows covering this deficit with less expensive and more affordable.

${ }^{2}$ Androshchuk G. O. Innovative policy and strategy of pharmaceutical companies: aspects of intellectual property. Topical issues of IP: collection of reports of the XXI International scientific and practical conference (Yalta, September 16-18. 2016). Kyiv: Information systems. - 2017. C. $11-30$. 
The main way to ensure effective IP protection in all countries is still a patent certifying the priority of the developer and copy protection in the territory of the patent. Almost all objects related to the Molecular structure of active pharmaceutical ingredients (hereinafter - API) and auxiliary components, dosage form, production technology, etc. are subject to patent protection.

As a rule, the patent validity period in the USA and Europe is 20 years and can be extended for drugs up to 5 years in the European Union (in Ukraine, the maximum patent validity period is 25 years). This period allows the company-developer to get the maximum profit from the sales of the drug, because during this time it is a monopolist in the market. However, in most cases, the real terms of such a monopoly do not exceed 10-15 years, since the peak of activity on patenting drugs usually falls at the end of the first phase of clinical trials.

In order to overcome this problem and increase the period of monopoly stay on the market of their drugs, many originator companies use a variety of strategies for" greening «the product. "Evergreen patents" (from the English. evergreen - evergreen) - is an artificial extension of the property rights of intellectual property arising from the patent on the API by further patenting various additional properties of the API, methods of its production, pharmaceutical compositions, which include the API, as well as diagnostic, therapeutic and surgical methods of treatment of people or animals with the help of drugs containing the $\mathrm{API}^{3}$.

Taking advantage of the monopoly right to the product, which is guaranteed by patent law, development firms maintain sufficiently high prices for drugs. The price of a patented drug can be tens, hundreds of times higher than the cost of production because its price includes: the cost of development and clinical trials, training of doctors and pharmacists, the cost of experimental equipment, the cost of monitoring the effect of the drug in the initial stage of its promotion to the market and, importantly, the cost of marketing.

At the same time, only about $20 \%$ of the costs fall on the work related to the synthesis of a new drug, and $80 \%$ - on its subsequent experimental and clinical study. In order to find a new drug substance, according to various estimates, it is required to synthesize from 3 to 10 thousand new compounds. The development of a new drug is quite time-consuming and expensive process. The cost of creating one new drug reaches $\$ 800$ million. The United States, and in preclinical studies and clinical trials of the original

${ }^{3}$ Soulier D. and Day N. Using Patent Extension to make up for lost time. MIP. 2016. No. 240. P. 1-7. 
drug have on average 8.5 years. This explains the high price of original drugs, which is not reduced in roki2.

The pricing policy of the company-developer of the original drug is clear. Significant funds spent on the search for the API molecule, drug research, bringing it to market, careful monitoring of possible adverse effects and interactions, while patent protection continues to operate, may be irretrievably lost in a few years. A generic drug, which is often reproduced by several companies at the same time, "inherits" all the properties, costs of effort, time and money as the original drug.

A generic medicinal product, as defined by the world health organization, is a medicinal product that is used interchangeably in medical practice with an innovative patented (original) product manufactured, as a rule, without a license from the Creator company and is sold after the expiration of the patent or other exclusive rights.

When evaluating generic drugs should keep in mind the following. The generic contains the same active drug (substance) as the original (patented) drug. Generic differs from the original drug auxiliary substances (inactive ingredients, fillers, preservatives, dyes, etc.). Differences are observed in the technological process of generics production.

And though it may be argued that the original is always the original, and the reproduced medium is only the reproduced medium. The common international generic name makes these drugs similar to the consumer, and the generic, usually for a lower price, more attractive ${ }^{4}$.

Manufacturers of original pharmaceutical brands protect their exclusive rights mainly through patent law. The implementation of patent protection for a particular molecule underlying drugs, provides for a ban on its reproduction for a period of time, the duration of which is 20 years. It should be borne in mind that from the beginning of testing a new molecule and the moment of obtaining a patent to the appearance of drugs on the market can take $10-15$, or even more years. Thus, the manufacturer of the original drug has an average of up to 5 years to compensate for costs and receive dividends from the original drug. By the end of this period, as a rule, there are attempts, taking advantage of the peculiarities of patent legislation, to extend the term of patent protection.

According to the report of the European Commission in the period 2007-2017 the number of applications for pharmaceutical patents doubled, with $87 \%$ of them being secondary, that is, not for the active substance itself, but for the method of its production, the dosage form and composition of the

\footnotetext{
${ }^{4}$ Financial Management in the NHS: Report on the NHS Summarized Accounts 2007-08. Twenty-second Report of Session 2008-09. URL: www.publications.parliament.uk.
} 
corresponding drugs, etc. This creates serious difficulties when creating generic versions.

The market entry of many generic drugs was deliberately delayed for 7 months or more, costing Europe 3 billion Euros. The reason for this were: patent clusters (each drug can be protected by dozens of patent families), through which the EU suspended the consideration of approximately 1300 applications for marketing permits for generics; litigation with generic companies initiated by originators; bilateral agreements between generic and innovative companies to delay the withdrawal of generics to markets; patent management during the life cycle of drugs; interference with the obtaining of marketing authorizations by e-companies ${ }^{5}$.

For example, in 1978, the main patent was obtained for the molecule omeprazole, starting from the late 90 -ies - for the magnesium salt of omeprazole, a method for treating diseases of the gastrointestinal tract using the levorotatory isomers of omeprazole, The s-enantiomer of the magnesium salt of these drugs in the form of trihydrate, a new crystalline form of omeprazole. Each of these patents allowed the developer to fight attempts to market generic omeprazole.

A similar situation has developed in Ukraine, where the Swedish firm ASTRA AB has filed the following applications for a patent of Ukraine. The essence of patent protection, which allows the patent owner to monopolize the use of its technical solution, thereby providing compensation for investments invested in it, quite accurately formulated $\mathrm{j}$. Robinson: "by slowing the spread of technological advances, patents create the conditions for the most significant advances to spread." Thus, the patent monopoly is an incentive for innovation. However, upon expiration of the patent, any pharmaceutical company, acquiring the right to produce its own version of the original drug, can create a generic drug.

\section{Strategies of pharmaceutical companies in connection with the end of patent protection of medicines}

For many years, the largest pharmaceutical companies, representatives of the so-called Big Pharma (Big Pharma), worked to prevent competition from representatives of the generic business-lobbied for the adoption of legislation that would extend the term of the patent monopoly, challenged in the courts the right to produce generic versions of original drugs, conducted thousands of clinical trials in the hope of patenting another way of using drugs, etc.

${ }^{5}$ IP Protection Incentivizes Innovation and Creates Jobs: A Message Worth Repeating. D. Kristina Lybecker, June 8, 2015. URL: www.ipwatchdog.com/.../ip-protection -incentive. 
However, now many of the representatives of Big Pharma are in such a situation that they are forced to join the number of those who were opposed all this time. Faced with the problem of completing the term of the patent monopoly on their original drugs, representatives of Big Pharma are increasingly inclined to the hybrid brand / generic model of their activities.

Four of the five largest multinational pharmaceutical corporations in the world ("Pfizer Inc.", "GlaxoSmithKline plc.", "Sanofi-Aventis" and "Novartis International AG") began to actively take a position in the generic business. Their example was followed by other major players in the pharmaceutical market. In 2009, Pfizer announced that it was expanding its generic drug product portfolio through two deals with companies based in India ${ }^{6}$.

Pfizer has expanded its agreement with Eurobond Pharma India to license the commercial rights to 60 generic drugs for more than 70 countries, in addition to the 70 drugs for which the original agreement was concluded. Pfizer also announced an agreement with another Indian company, Claris Lifesciences Limited, which includes 15 generic parenteral drugs that Pfizer will market in the United States, Europe and Australia under its own trademarks.

The company plans to expand the range of generic drugs through licensing deals, acquisitions and in-house developments. The market for generic drugs is huge, growing faster than it may seem at first glance, and that is why Pfizer is making efforts to "grow" this subsection. In addition to India, the company relies on the markets of countries such as China, Brazil, Mexico, Russia, Turkey and the middle East. Annual sales in these markets are expected to generate an additional \$ 3 billion. USA. And the middle East is called one of the most promising regions for sales growth.

Novartis has announced that it is ready to pay 925 million Euros (1.294 billion dollars).) for the portfolio of parenteral generic drugs of the Oncology division of the Austrian company "Ebewe Pharma", which specializes in anti-cancer drugs such as carboplatin, cisplatin, doxorubicin and epirubicin. This company already has extensive business experience in the generic market. So, since 2003 it has its own generic division "Sandoz". Since then, other generic firms have been merged under this brand, including Canada's Sabex Holdings Ltd."(September 2004. the transaction price) of \$ 565 million.), Denmark's Durascan (July 2004; valued at \$ 25 million in 2003), Germany's Hexal AG (which is also a key player in the market for

\footnotetext{
${ }^{6}$ Worker L. the Problem of evergreen patents in Ukraine. Intellectual property in Ukraine. 2012. No. 8. P. 20-26.
} 
similar bio preparations) and the us' Eon Labs (the latter both) in June 2005; the deal is valued at $\$ 7.4$ billion $)^{7}$.

As for Sanofi-aventis, the company is particularly active in acquisitions in the generic business. It took over the Czech company "Zentiva" (the deal is valued at 2.34 billion dollars.), which occupies a strong position in Eastern Europe and Russia. Then "Sanofi-aventis" acquired two more companies: a private Mexican firm

"Kendrick Farmaceutica "(the amount of the transaction was not disclosed) and the Brazilian "Medley Pharmaceuticals Ltd." (the deal is valued at \$ 688 million.).

The next company to expand its presence on a multinational scale is GlaxoSmithKline, which in 2009 took care of $16 \%$ of Africa's largest generic company Aspen Pharmacare (a deal valued at \$ 410 million). USA.) These companies have also expanded their strategic partnership, including the acquisition in 2008 of Aspen Pharmacare rights to 20 generic drugs that

Since 2010, GlaxoSmithKline has been marketing under its own brand names in 95 emerging markets, including China and India. In addition, the British pharmaceutical giant has signed an agreement with the American "Prasco Laboratories" that dose-recovery and provide marketing and distribution of many generic drugs "GlaxoSmithKline" in the United States.

Recently, the British company announced an agreement with the Indian generic manufacturer "D Reddy's". Through this deal, GlaxoSmithKline gains access to Reddy's now existing product portfolio, as well as products that will appear in the future, all to more than 100 drugs from the group of antidiabetic, cardiovascular, gastroenterological, painkillers and Oncology products that will market in markets that are developing outside India. The Swiss company "Roche" acquired the American biotechnology company Genentech "(the deal is estimated at 46.8 billion dollars) ${ }^{8}$.

The Company "Merck \& Co." entered the market segment of generic drugs by establishing a new division. "Merck BioVentures", which will focus on similar biological products (biogenerics). The company expects to get at least 5 other generic bio preparations in its bio-product portfolio. In order to help yourself gain a foothold in this growing sector, Merck \& Co. "announced that it plans to buy a portfolio of similar biopharmaceutical products of the American company "Insmed Inc." together with its production facilities located in boulder, Colorado (the deal is valued at \$130 million).

\footnotetext{
${ }^{7}$ Financial Management in the NHS: Report on the NHS Summarized Accounts 2007-08. Twenty-second Report of Session 2008-09. URL: www.publications.parliament.uk.

${ }^{8}$ Worker L. the Problem of evergreen patents in Ukraine. Intellectual property in Ukraine. 2012. No. 8. Pp. 20-26.
} 
The company's product portfolio includes two products that affect the granulocyte colony stimulating factor (gra - nulocyte-colony stimulating factor), which are currently undergoing phase III and phase I clinical trials, respectively. "Merck \& Co. "Also, the presence of its generics in the market of Japan, where its subsidiary "Banyu Pharmaceutical Co." is stationed. Ltd.", which signed an agreement with "Mylan Inc." to promote two key generic cardiovascular drugs in the Japanese market.

Active positions are also occupied by Japanese companies. Thus, "Daiichi Sankyo" completed the acquisition of the Indian "Ranbaxy Laboratories Limited", investing in it a total of $\$ 4.6$ billion. I suggested-Shi create a hybrid brand-generic business (although subsequent problems in production and the introduction of stricter standards of drug approval by regulators led to a record for "Ranbaxy" losses amounted to 335.8 billion Japanese yen, or $\$ 3.5$ billion $)^{9}$.

However, not all companies leave their original drugs in a helpless state. Thus, Pfizer applied an original way to maintain the image of brands, starting to implement in the United States the program "MAINTAIN" ("Support") to provide free access to more than 70 drugs of its own production for those who lost health insurance as a result of job cuts. Free treatment with original drugs will be available - but for 1 year or until the one that became unemployed again received an insurance policy So Pfizer is trying to support not only the market of its shares, but also encourages patients to take original drugs rather than switch to their generic versions as a way to save money.

The most important problem facing all large representatives of Big Pharma is the end of the patent monopoly. In the next 4 years, the patent monopoly will expire with approximately 70 original products. For example, the Corporation "Pfizer" is a number of products, including mega blockbuster, the drug Lipitor / atorvastatin (atorvastatin), used in hypercholesterolemia. According to some estimates, Sanofi - Aventis drugs, which account for more than $20 \%$ of all sales of this company in the us pharmaceutical market, are soon facing competition from generics, including products such as Plavix/plavix (clopidogrel; marketing together with Bristol - Myers Squibb), Eloxatin / Oxol (oxaliplatin) and Taxotere / TaxoTer ${ }^{\circledR}(\text { docetaxel })^{10}$.

${ }^{9}$ Androshchuk G. O. Intellectual property, innovations, economic development: optimal ratio. Intellectual property in Ukraine. 2016. No. 3. Pp. 4-7.

${ }^{10}$ IP Protection Incentivizes Innovation and Creates Jobs: A Message Worth Repeating. D. Kristina Lybecker, June 8, 2015. URL: www.ipwatchdog.com/.../ip-protection -incentive. 
Lost patent protection back in 2012; several other drugs are also on the verge of ending patent protection.

The drug company "Merck \& Co." Cozaar (losartan) was faced with the need to resist competition from gene-RICS in 2010.

However, the end of the patent monopoly is only the tip of a growing generic iceberg. According to experts, the global market for generic drugs is growing by about $10-15 \%$ per year, and its growth will continue for several more years, especially in the United States. With the coming to power in the United States, the government of Barack Obama and the Democrats, who form a majority in both houses of Congress, increased political support for the generic drug market. As price sensitivity increases in the pharmaceutical market, health care reform is expected: Americans are becoming more inclined to buy cheaper generic preparation6.

An increase in the generic drug market is also expected in Japan. Thus, over the past 3-4 years, its volume in the land of the Rising Sun has increased by about $7 \%$ per year, and the government is taking steps to further increase it to $30 \%$ in 2012 (Schofield I., 2009). The favorable situation in the Japanese market is already attracting foreign companies. Thus, "Teva Pharmaceutical Industries Ltd." established a joint venture (equally owned venture) with local" Kowa Pharmaceutical Company Ltd.", and the Icelandic "Actavis" with "Aska Phar-maceutical" organized in 2008 a joint venture "Actavis ASKA Co. Ltd."

In Europe, price pressures have encouraged most national governments to support the consumption of generic drugs in order to reduce rising health costs. Thus, according to the report of the national audit office of Great Britain (National Audit Office) in 2008, the National health service (National Health Serve - ice) managed to save almost 400 million pounds (657.3 million dollars).) Through the use in the health care system of cheaper generic drugs, especially the therapeutic group statins ${ }^{11}$.

At the level of the European Union as a green light generics acted dual system of approval of generic drugs: on the one hand, was introduced decentralized, and on the other - centralized procedural.

Their approval, which provides generic drugs with access to all EU markets. Legislation on similar biological products has also been developed in Europe. That is why, in this context, "Merck \& Co." steps towards similar biopharmaceutical products are not without meaning. European experience has shown that the market for similar biological products has potential, and the legislation for the approval of these drugs in the United States is very similar to the European path.

${ }^{11}$ Soulier D. and Day N. Using Patent Extension to make up for lost time. MIP. 2016. No. 240. P. 1-7. 
Another factor that stimulates the reorientation of representatives of Big Pharma to generics is the significant growth of emerging markets, which make up most of the business of multinational pharmaceutical companies in Asia. The importance of pharmaceutical markets of countries that are developing for Big Pharma will continue to grow, and global strategies for their development will increasingly take into account both the medical needs and commercial opportunities of such countries.

According to experts, the volume of 10 major emerging markets will grow to $\$ 168$ billion by 2015 . compared to $\$ 67$ billion. in 2005 , the Reason for this is the increase in the number of middle-class people in these countries who need better drugs and medical care, as well as the increase in the number of chronic diseases, especially cardiovascular diseases.

Total sales growth in emerging markets, including Central and South America, Africa and much of Eastern Europe and Asia, more than doubled, and the population of developing countries reached 5 billion people by 2015 . At GlaxoSmithKline alone, sales in these markets reached 2.3 billion pounds (\$3.75 billion) last year.), an increase of $12 \%$.

The head of the R \& D division of "AstraZeneca" in the Asia-Pacific region and Japan, Patrick Keohane (Patrick Keohane), noted that sales of the company's products in emerging markets last year reached 4.27 billion dollars. their growth was $16 \%$. However, in China, for example, only $\$ 8$ a year is allocated to health care per capita., So the company had to look for an answer to the question: how best to meet the medical needs of such markets, which could not but affect the R \& D strategy.

At present, AstraZeneca's strategic efforts to enter the market of biological products have come to the fore, and such products account for about a quarter of the new drugs in the company's portfolio.

AstraZeneca will continue its steps towards development bioproducts, made possible by the acquisition of MedImmune Inc."12.

While Asian and other markets in developing countries may provide opportunities for Big Pharma to grow, issues such as IP protection, parallel imports and counterfeit drugs still cause transnational corporations serious problems.

Representatives of Big Pharma are betting on the generic market, considering a hybrid brand-generic strategy as a way to optimize, pushed to this by economic and regulatory conditions. But will such a strategy work? Most large multinational corporations believe that Yes, and have already taken the appropriate decision.

12 Androshchuk G. O. Ukraine in The global index of intellectual property. Intellectual property in Ukraine. 2017. No. 12. P. 60. 
Other companies, whose products will face the end of the patent monopoly after some time, may soon adopt the same strategy of reorientation to the generic business. Thus, AstraZeneca's drugs, such as Arimidex/arimidex (anastrozole), Symbicort/Symbicort Turbuhaler (budesonid + formoterol) and Seroquel/Seroquel TM (quetiapine), will face generic competition in the next two years, although the company has not yet made steps towards the generic market.

However, not everyone will choose the strategy of generic drugs. Companies whose business is based on R \& D and which have not yet been affected by the issue of ending patent exclusivity are unlikely to follow this strategy. So "Roche", "Bayer Schering Pharma" and "Abbott Laboratories Inc." only partially subjected to competition from generics. A few years ago, Roche said it was not interested in generic drugs because not many products would lose their patent monopoly in the near future ${ }^{13}$.

This may change, and as the generic drug market continues to grow, generic companies will occupy an increasing share of the major pharmaceutical markets. Thus, "Teva" begins to expand into the Japanese market, "Mylan" strengthens its position in India and in the Eastern European generic markets. "Lupin Pharmaceuticals Inc." Indian company acquired $51 \%$ of HP "Multicare Pharmaceuticals Philippines Inc." and is looking for opportunities to grow its business in Asia, Eastern Europe and Latin America.

Who can $\mathrm{R} \& \mathrm{D}$ companies that plan to enter the generic drug market rely on? One of the targets is Ratiopharm, the No. 1 generic company in Germany, up for sale. No specific buyer has yet been announced, although many bidders have been named, including Sanofiaventis and Teva, and later, according to Bloomberg reports, investment groups Apax Partners and Warburg Pincus.

Another possible target is the Icelandic company "Actavis Group", which brought to the market of Germany, Ireland and the Netherlands a generic version of pantoprazole, after the patent monopoly on the original drug Protonix Company "Wyeth" ended. However, the reorientation of Big Pharma to the generic market does not end there. The opposite process is predicted, when the largest representatives of the generic business will take over R \& D companies.

${ }^{13}$ Androshchuk G. O. Innovative policy and strategy of pharmaceutical companies: aspects of intellectual property. Topical issues of IP: collection of reports of the XXI International scientific and practical conference (Yalta, September 16-18. 2016). Kyiv: Information systems. -2017 . C. $11-30$. 
Only companies - leaders of the generic sector of the market, which are called "young wolves", manage to break through the patent protection of Big Pharma. Like innovative companies, these companies have their product lines of generic drugs in various stages of readiness for placement on the market. This requires constant analysis of the patent portfolio of originators, which allows to identify "weaknesses" or "workarounds" that can be overcome in the development of generics. Not every company can afford to participate in lawsuits defending the right to bring generics to the market. It is reported that the average cost of court costs in such cases is $\$ 2$ million. USA.

The analysis, monitoring and application of patent information requires the participation of consultants with specialized training. After all, a patent for a molecule of an active substance is only the tip of the iceberg of protection of the original drug. Interesting facts about drugs and IP on the example of the original drug atorvastatin report specialists "Generics Web Pty Ltd" - Australian firm of patent analysis and search.

On the EU market (in the UK) Lipitor was first introduced in 1996, and the validity of the patent for API ends in 2011 there Are about 230 families of patents relating to drugs atorvastatin, namely the molecule of the active substance, the composition of drugs, the production process, application, etc. Only $80 \%$ of them mention atorvastatin. There are more than 120 owners of the relevant patents, some of them are generic companies that develop the drug atorvastatin in such a way as not to infringe on the IP of Big Pharma. Among them, the leaders are "Biocon" (API), "Teva "(API and drug), "Lek". The main emphasis in the development is on the use of amorphous, not crystalline atorvastatin, and the activity of obtaining patents in the last 5-6 years has increased significantly. That is, the concept of development of generic drugs in compliance with IP rights is not something symbolic and abstract ${ }^{14}$.

By obtaining patents relating to original drugs, within 2-3 years after their introduction to the market, the leaders of the generic industry contribute to the intellectual sphere. The first generic drug on the market in the United States becomes the subject of $50-80 \%$ of all prescriptions within 10 weeks after its introduction. The share of the market, which is occupied by the pioneer generator, in monetary terms is approximately $57.6 \%$. At the same time, the retail price of the drug is lower than the original by about $40.8 \%$.

${ }^{14}$ IP Protection Incentivizes Innovation and Creates Jobs: A Message Worth Repeating. D. Kristina Lybecker, June 8, 2015. URL: www.ipwatchdog.com/.../ip-protection -incentive. 


\section{Pharmaceutical market and patent protection of medicines in Ukraine}

The pharmaceutical industry is a high-tech industry with a high level of intensity of research and development (science intensity) and is one of the most profitable in the world. As noted in the explanatory note to the resolution of the Verkhovna Rada of Ukraine "on holding parliamentary hearings on the topic" on the current state and prospects of development of the pharmaceutical industry of Ukraine "the high-level discussion of the current state and prospects of development of the pharmaceutical industry is caused by serious threats associated with the further functioning of this very important branch of the national economy, taking into account global trends.

Despite a certain increase in production and sales of pharmaceutical products, domestic manufacturers continue to lose ground not only in foreign but also domestic markets. According to the results of 2010, the products of 470 foreign and only 150 Ukrainian (that is, in three smaller numbers) pharmaceutical companies were presented in Ukraine. According to the Antimonopoly Committee of Ukraine, 10 Ukrainian and 10 European companies control half of the market ${ }^{15}$.

Of the 18 thousand registered names of drugs in Ukraine produced only 5.5 thousand. Drugs of foreign origin account for more than $76 \%$ of the total market. More than $90 \%$ of medicines are technologically obsolete, which have already expired 20-year term of patent protection. The production of modern drugs requires increasing investment in research activities (from 800 million to 1 billion dollars). The United States for a drug), which is unaffordable for domestic producers. This, in turn, will continue to reduce them. Competitiveness, and after a certain time can lead to mass bankruptcy of enterprises in the industry.

According to statistics, citizens of Ukraine annually spend 32 billion UAH on medicines., which accounts for $90 \%$ of all drug costs in the country. The state assumes only $10 \%$ or 4 billion in recent years in Ukraine there is a tendency to reduce the level of consumption of drugs in kind. However, the level of consumption of drugs per capita in monetary terms has doubled from $\$ 27$ to $\$ 54$, and in 2013 this figure reached $\$ 80$.

Ukraine ranks 4 th in terms of drug costs per capita among the CIS countries (after Russia, Belarus and Kazakhstan). In the EU, this figure is much higher, the level of spending on drugs per capita in the Czech Republic is $\$ 331$, Slovakia $-\$ 254$, Poland - \$154. The reason for this situation-low purchasing power of citizens of Ukraine, as well as low social protection of

\footnotetext{
${ }^{15}$ Financial Management in the NHS: Report on the NHS Summarized Accounts 2007-08. Twenty-second Report of Session 2008-09. URL: www.publications.parliament.uk.
} 
the population in the field of drugs. The domestic system of pharmaceutical support is based on the vast majority of drugs in conditions of extremely limited budget funds. Thus, at present, the country cannot provide drugs even preferential categories of the population ${ }^{16}$.

A significant decrease in the availability of treatment to citizens of Ukraine is caused by the increase in prices for paid treatment and drugs, which has been particularly noticeable over the past 3-4 years. Thus, in 2009 the cost of official paid medical services increased by 20\%, in 2010-by another $10 \%$. The official rise in the price of medicines in 2009 amounted to more than $40 \%$, in 2010 medicines rose by another 6-10\%. The increase in prices for medicines has been lasting for a long time and in 2011.currently, there is a large gap between the ability of society to Finance health care costs and the ever-increasing need to increase them. In Ukraine, up to $25 \%$ of all expenditures in the health care system are related to drug provision. At the same time, the return on investment remains low: there is no increase in life expectancy, reduction in mortality and the number of serious complications.

According to the results of the first half of 2013, the volume of pharmacy sales of drugs in the country amounted to UAH 14.6 billion for 625 million packages, which is $15.7 \%$ in cash and $3.8 \%$ in kind more than last year. In physical terms, that is, in packages, the majority of drugs sold (65.4\%) were of domestic production. At the same time, in monetary terms, the situation is the opposite: Ukrainian consumers paid $68.6 \%$ for imported medicines, while domestic consumers paid $31.4 \%$ of the total amount spent on medicines.

The volume of the pharmaceutical market of Ukraine in 2013 amounted to 36 billion UAH., which is a record of the last six years. On the territory of Ukraine there are more than 100 pharmaceutical enterprises that produce their products according to European standards, a developed network of 20 thousand pharmacies and $\$ 120$ million of investments in the pharmaceutical industry in 2013.

Despite the rather dynamic pace of development in comparison with other sectors of the economy, the pharmaceutical industry of Ukraine has a number of serious problems. One of them is imperfection of the legislative base in the sphere of circulation of drugs, which leads to: containment of development and introduction in manufacture of generic drugs, the creation of unequal conditions of access to the market of drugs of domestic and foreign production, reducing the effectiveness of measures to counter

${ }^{16}$ Androshchuk G. O. Ukraine in The global index of intellectual property. Intellectual property in Ukraine. 2017. No. 12. P. 60. 
production and trafficking of counterfeit drugs, IP infringement in the sphere of circulation of medicines.

Over the past 5 years in Ukraine, the total number of applications for inventions under the national procedure has increased more than 2 times. At the moment, 14205 drugs are registered in Ukraine, which cover all pharmacological groups. Of them: 3719-HP domestic and 10486-foreign production. The highest growth rates (2.6 times) in the context of industries demonstrates the division "Medicines for therapeutic, dental or hygienic purposes". The most active filing of applications for inventions is recorded in such industries as medical technology, measurement and pharmaceuticals. At the same time, there is an active patent expansion of foreign pharmaceutical campaigns: out of the total number of foreign applications for inventions and utility models filed during 2004-2008 in Ukraine, drugs account for $22 \%$, while among national applications-only $6 \%$. With 510 patents for inventions issued in 2008 (according to the IPC class A61 medicine or veterinary medicine; hygiene), 328 (64\%) belong to foreign applicants and $182(36 \%)$ - to national applicants ${ }^{17}$.

Of all drugs currently available on the Ukrainian market, and which are considered the most promising, all are patented, which may limit the use of more affordable generics. These are patents on the molecule itself (e.g. raltegravir), a continuation of the original patent for 5 years after the expiration of the 20-year term (e.g. efavirenz) or patents on a combination of old molecules (e.g. TDF / FTC or LPV/r).

Of the drugs that are not yet used, but in the near future can be registered, many are protected by patents for inventions on the molecule (eg. rlpr, etravirine, fosamprenavir, maraviroc, coblt) or patents that justify the improvement of the original composition (eg. patent for atazanavir bisulfate, manufacture of darunavir intermediates, improved pharmacokinetics of elvitagravir in combination with RTV).

However, it is noted that the vast majority of drugs are not protected by patents and are for use in the public domain. So only $25 \%$ antivirus drugs for the treatment of hepatitis / AIDS remain patented.

It should be noted that, according to WIPO, applications for inventions in the pharmaceutical industry have steadily declined since 2007. In the history of the global pharmaceutical industry, 2012 will go down as a year of patent collapse-patent protection lost more than 40 brands with annual sales of about $\$ 35$ billion. USA. According to expert estimates, by 2015 the patent

${ }^{17}$ Worker L. the Problem of evergreen patents in Ukraine. Intellectual property in Ukraine. 2012. No. 8. P. 20-26. 
protection will lose drugs-blockbusters, the total annual sales of which is 150 billion dollars ${ }^{18}$.

From an economic point of view, the strengthening of IP protection leads to two contradictory results: the patent holder is granted a monopoly right for a certain period, which leads to a weakening of competition and an increase in prices in the market for the sale of patented products. Strengthening patent protection increases incentives for innovation by generating monopoly profits that offset the costs of research and development. Increased incentives provide long-term strategic benefits: improved technology and improved product quality.

\section{CONCLUSIONS}

The introduction of new medicines into circulation is controlled by the national administrative bodies responsible for the quality, efficiency and safety of medicines, the so-called pharmacological supervision bodies, which carry out the registration of the drug and confirm it with a special document. This registration is carried out on the basis of data confirming the clinical efficacy and safety of the drug.

It should be noted that the permissive administrative procedure for commercial use is established by law not only for medicines but also for some other products: food and barberry additives, cosmetics, medicines for animals or veterinary biological products, plant protection products, agrochemicals, medical devices, etc. However, this monograph will consider only those provisions of legislation and procedures relating to medicines for humans.

Despite the rather dynamic pace of development in comparison with other sectors of the economy, the pharmaceutical industry of Ukraine has a number of serious problems. One of them is imperfection of the legislative base in the sphere of circulation of drugs, which leads to: containment of development and introduction in manufacture of generic drugs, the creation of unequal conditions of access to the market of drugs of domestic and foreign production, reducing the effectiveness of measures to counter production and trafficking of counterfeit drugs, IP infringement in the sphere of circulation of medicines.

Over the past 5 years in Ukraine, the total number of applications for inventions under the national procedure has increased more than 2 times. At the moment, 14205 drugs are registered in Ukraine, which cover all pharmacological groups.

${ }^{18}$ IP Protection Incentivizes Innovation and Creates Jobs: A Message Worth Repeating. D. Kristina Lybecker, June 8, 2015. URL: www.ipwatchdog.com/.../ip-protection -incentive. 


\section{SUMMARY}

Countries that have strengthened the IP legal protection regime provide strategic advantages and benefits. However, for the transition economies, which include Ukraine, the economic situation will be different.

This is due to a number of reasons:

1) Ukraine is mainly a user, not an exporter of innovative products, and therefore does not receive the monopoly profits created by patent protection. Domestic consumers (patients) suffer losses as a result of price increases.

2) since the drug market in our country is relatively small in relation to global demand, the measures taken by Ukraine to strengthen the protection of patents practically do not affect the incentives for additional research.

This is due to the difference between the cost of generic drugs supplied by manufacturers in developing countries and the price of drugs in industrialized countries.

\section{REFERENCES}

1. Soulier D. and Day N. Using Patent Extension to make up for lost time. MIP. 2016. No. 240. P. 1-7.

2. Worker L. the Problem of evergreen patents in Ukraine. Intellectual property in Ukraine. 2012. No. 8. P. 20-26.

3. IP Protection Incentivizes Innovation and Creates Jobs: A Message Worth Repeating. D Kristina Lybecker, June 8, $2015 . \quad$ URL: www.ipwatchdog.com/.../ip-protection -incentive.

4. Androshchuk G. O. Innovative policy and strategy of pharmaceutical companies: aspects of intellectual property. Topical issues of IP: collection of reports of the XXI International scientific and practical conference (Yalta, September 16-18. 2016). Kyiv: Information systems. 2017. C. 11-30.

5. Financial Management in the NHS: Report on the NHS Summarized Accounts 2007-08. Twenty-second Report of Session 2008-09. URL: www.publications.parliament.uk.

6. Androshchuk G. O. Intellectual property, innovations, economic development: optimal ratio. Intellectual property in Ukraine. 2016. No. 3. P. 4-7.

7. Androshchuk G. O. Ukraine in The global index of intellectual property. Intellectual property in Ukraine. 2017. No. 12. P. 60.

\section{Information about the author:}

Rachinska I. M.,

Candidate of Law, Associate Professor, Associate Professor at the Department of Administrative,

Criminal Law and Procedure, International University of Business and Law 37-A, 49 HGD str., Kherson, 73040, Ukraine 